\title{
Desafios para o atual governo na área de comunicação
}

\author{
Communication policy related challenges for the current Brazilian \\ government
}

\section{Desafíos para el gobierno brasileño actual referentes a las políticas de comunicación}

Marcos Dantas | prof.marcosdantas@gmail.com

Universidade Federal do Rio de Janeiro (UFRJ), Escola de Comunicação. Rio de Janeiro, RJ, Brasil.

\section{Resumo}

São muitos os desafios a serem enfrentados pelo Ministério das Comunicações no mandato que se iniciou em janeiro de 2015. Trata-se, aqui, especificamente dos desafios para regulamentar as comunicações no país, apresentando elementos para pensar um modelo estratégico que supere a ideia de combate a determinados grupos de mídia. A partir da visão de que os meios de comunicação não são apenas veículos de informação noticiosa ou jornalística, e sim espaços de entretenimento e de acesso à cultura e educação no sentido mais amplo dessas palavras -, defende-se a ideia de um projeto de regulamentação que favoreça a competição e diversifica-ção de vozes e imagens que fortaleçam a cultura brasileira, nacional e regional, com ampla repercussão social.

Palavras-chave: Política de comunicação; Marco regulatório das comunicações; Regulamentação da mídia; Democratização dos meios de comunicação; Lei da Mídia Democrática.

\begin{abstract}
There are a number of challenges to be tackled by the Ministry of Communications under the mandate that began last January. Here a specific approach deals with the challenges to regulate the Brazilian media, presenting elements to develop a strategic model that should transcend the idea of combatting certain media groups. From the viewpoint that the mass media are more than mere vehicles for transmitting news or journalistic information to the degree that they also are entertainment organs and ways of accessing culture and education - in the broadest sense of those words - the government must develop a regulation project stimulating competition and diversification of voices and images that provides for strengthening Brazilian national and region-al culture, a project that should have broad social effect.
\end{abstract}

Keywords: Communication policy; Regulatory framework for communications; Media regulation; Democratization of the mass media; Lei da Mídia Democrática (a bill of popular initiative to democratiza-tion of Brazilian media). 


\section{Resumen}

Son muchos los desafíos que el Ministerio de las Comunicaciones tendrá que enfrentar en el mandato que se inició en enero del 2015. Se trata aquí, específicamente, de los desafíos para reglamentar las comunicaciones en Brasil, presentando elementos para pensar un modelo estratégico que supere la idea de combatir determinados grupos de medios. A partir de la visión de que los medios de comunicación no son apenas vehículos de información noticiosa o periodística y sí espacios de entretenimiento y de acceso a la cultura y a la educación - en el sentido más amplio de estas palabras - se defiende la idea de un proyecto de reglamentación que favorezca la competencia y la diversificación de voces e imágenes que fortalezcan la cultura brasileña, nacional y regional, con amplia repercusión social.

Palabras clave: Política de comunicación; Marco reglamentario de las comunicaciones; Reglamentación de los medios de comunicación masivos; Democratización de los medios de comunicación masivos; Lei da Mídia Democrática (proyecto de ley de iniciativa popular para democratización de los medios de comunicación masivos en Brasil).

Declaração de conflito de interesses: não há.

Histórico do artigo: Submetido: 6.mar.2015 | Aceito: 13.mar.2015 | Publicado: 31.mar.2015

Licença: CC BY-NC atribuição não comercial. Com essa licença é permitido acessar, baixar (download), copiar, imprimir, compartilhar, reutilizar e distribuir os artigos, desde que para uso não comercial e com a citação da fonte, conferindo os devidos créditos de autoria e menção à Reciis. Nesses casos, nenhuma permissão é necessária por parte dos autores ou dos editores. 
A indicação do deputado Ricardo Berzoini para o comando do Ministério das Comunicações neste início de segundo mandato da presidente Dilma Rousseff acendeu novas esperanças de que, finalmente, venha a avançar a construção de um novo marco regulatório que "democratize a mídia", como se costuma a dizer. O ministro tem declarado, em sucessivas manifestações à imprensa, que vai abrir o debate sobre o tema e, em janeiro, já fizera os primeiros contatos com os movimentos políticos que, há muito tempo, se empenham em pautar a discussão, entre eles, principalmente, o Fórum Nacional pela Democratização das Comunicações (FNDC).

Por outro lado, ele tem declarado não possuir projeto próprio e nem estar muito disposto a considerar os projetos já existentes, entre eles o até hoje desconhecido, mas muito citado, anteprojeto que teria sido elaborado pelo ex-ministro Franklin Martins, ainda nos meses finais do governo Lula, e o Projeto de Lei de Iniciativa Popular (PLIP) que segue aguardando as assinaturas necessárias para ser apresentado à Câmara dos Deputados. Este, no momento em que estas linhas estão sendo escritas, é, a rigor, o único projeto disponível para discussão pública ${ }^{i}$, embora também existam muitos outros em tramitação no Congresso que não tratam, propriamente, de uma regulamentação abrangente mas, sim, de tópicos como, por exemplo, da regionalização da programação de rádio e TV, ou do direito de resposta, ou da regulamentação da profissão de jornalista etc.

É possível que a decisão da presidente Dilma de pôr, no Ministério das Comunicações, um político claramente comprometido com algum programa de democratização dos meios esteja fortemente relacionada ao comportamento abertamente partidário, intelectualmente desonesto, até mesmo mentiroso, adotado, nos últimos anos, pelos grupos mediáticos brasileiros e pelo conjunto dos seus profissionais de imprensa. A campanha que essas empresas e seus jornalistas, sejam os colunistas mais afamados, sejam os meros repórteres e redatores, têm feito contra o governo federal, liderado pelo PT, só se compara àquela enfrentada por Getúlio Vargas, nos anos 1950. Recrudesceu na última campanha eleitoral, inclusive explorando exaustivamente mas sempre facciosamente, as revelações da investigação policial denominada "Operação Lava Jato". Alguma proposta sob o crivo de "democratização da mídia" visaria, assim, abrir caminho para enfraquecer o poder detido por esses grupos para formar opinião e fabricar consensos, também permitindo criar espaço para a expansão de novos veículos comunicadores que favorecerem maior pluralidade de ideias no ambiente mediático e jornalístico.

O governo, no entanto, dá fortes indicações de não saber muito bem como fazer isso. E nem o seu principal partido de sustentação, o PT. E será este o seu maior desafio, no quadriênio que se inicia. Não poucos projetos deste já longo ciclo petista-peemedebista de governo foram formulados e implementados sem "ampla consulta". Não raro porque já existia no PT acúmulo de conhecimento e formulação sobre algum tema, como é o caso do "Bolsa Família", evolução do "Fome Zero", solução assistencialista que já vinha sendo paulatinamente elaborada desde os tempos em que o sociólogo Herbert de Souza, o "Betinho", iniciou sua "Ação pela Cidadania, contra a Fome, a Miséria e pela Vida". Poder-se-ia citar também os programas ou decisões no campo econômico, como políticas para baixar taxas de juros, ampliar crédito, ou o "Luz para Todos", ou o novo regime de exploração do pré-sal, todos definidos após estudos e discussões que, com certeza, ficaram limitados aos, digamos, "especialistas". O Marco Civil da Internet também teve início como um projeto de lei elaborado por um núcleo especialista, daí retrabalhado nos gabinetes do Ministério da Justiça para, em seguida, ser submetido a um certo debate público, antes de, na sua forma final, ter sido enviado para tramitação e votação no Congresso.

Para regulamentar os meios de comunicação, o governo também poderia elaborar um anteprojeto e submetê-lo ao debate público, antes de enviá-lo ao Congresso. Seria o seu papel. Ao optar por "colher as contribuições da sociedade", pode estar avaliando a real correlação de forças e, sobretudo, a capacidade de

i Disponível em: http://www.paraexpressaraliberdade.org.br/images/docs/LeidaMidiaDemocratica.pdf. 
mobilização da militância pró-"democratização". É possível que ainda ressoe nos gabinetes palacianos os ecos do mal- sucedido debate sobre o projeto da Agência Nacional do Cinema e do Audiovisual (Ancinav) uma proposta perfeitamente coerente com as ideias da militância petista já engajada no debate, mas incompreendido e, por isso, não apoiado pelas principais lideranças do partido, pois o tema "comunicações" nunca esteve, de fato, entre as suas prioridades políticas. Se, agora, parece ocupar um espaço mais visível, isto se deve mais a uma (atrasada) reação à postura antipetista uníssona das corporações mediáticas $e$ de seus jornalistas, do que a uma antevisão prospectiva que entenda a importância, não apenas política, mas também econômica e cultural, da "mídia" no capitalismo contemporâneo. Implica dizer que, sem essa compreensão, a reforma que se anuncia, se é que vai acontecer, poderá resultar numa emenda pior do que o soneto. Se o objetivo for apenas enfraquecer as corporações mediáticas nacionais, como reação, embora muito justificada, aos malefícios que elas têm feito à democracia liberal brasileira, a consequência poderá acabar sendo a entrega do nosso mercado econômico, cultural e profissional a corporações mediáticas estrangeiras, sobre-tudo estadunidenses, que hoje já dominam amplamente o segmento de televisão por assinatura e de internet. Qualquer projeto de regulamentação, pois, precisaria ponderar a necessidade de favorecer a competição e diversificação de vozes e imagens no mercado de ideias, com a obrigação de defesa e fortalecimento da cultura brasileira em sua variedade nacional e regional, inclusive como campo de geração de empregos e renda.

\section{Pensar um modelo estratégico}

O primeiro desafio que o governo Rousseff precisaria encarar, seria pois, digamos assim, "teórico": qual o objetivo da regulamentação, de um ponto de vista estratégico, de um ponto de vista que discuta o país que queremos e, não, apenas, os grupos de "mídia" que não queremos... Vivemos numa sociedade mediatizada. Os meios não são apenas veículos de informação noticiosa ou jornalística. Os meios, entre eles incluindo-se a internet, são o principal se não, para milhões e milhões de pessoas, o exclusivo, quase único, espaço de entretenimento e de acesso à cultura, no conceito mais amplo de "cultura". É o espaço de educação (também no sentido mais amplo de "educação"), é o espaço de reafirmação e compartilhamento do senso comum. A maior parte dos conteúdos veiculados pelos meios eletrônicos mas também pelos impressos, não é notícia jornalística, nem trata diretamente de política. E a imensa maioria das pessoas em contato com esses meios não está interessada em notícias, muito menos em política. Os militantes, sim, só têm olhos para o noticiário jornalístico e para os possíveis enviezamentos políticos ou ideológicos que parecem se manifestar aqui ou acolá...

O êxito, medido em audiência ou circulação, de determinado canal de televisão ou desse jornal ou daquela revista não está pois necessariamente relacionado a poderes políticos melífluos que os empresários pareçam possuir, mesmo que tais poderes possam ser de alguma ajuda. O êxito está relacionado a gosto. Como se forma esse gosto é tema para discussão que ultrapassaria em muito o limite de páginas deste artigo, mas, certamente, ele é, em grande medida, produzido pelas condições materiais e culturais nas quais as pessoas vivem, desde quando iniciam seus processos de socialização. Os meios, certamente, na busca das maiores audiências, contribuem para reforçar certos gostos medianos (para não dizer, medíocres), mas bem sabemos que os processos de socialização, quando mais ricos e diversificados culturalmente, muito ajudam a estabelecer filtros críticos a tais ofertas mediocrizantes. Ou seja, o mais provável é que os meios, de fato, busquem se ajustar a um certo gosto "popular"; e, quanto mais êxito tenham nesse ajuste, maior

ii FERREIRA, J. Ancinav: omissão ou missão? Disponível em: http://csbh.fpabramo.org.br/o-que-fazemos/editora/teoria-e-debate/ edicoes-anteriores/debate-ancinav-omissao-ou-missao; NASSIF, L. A proposta da Ancinav. Disponível em: http://www1.folha.uol. com.br/fsp/dinheiro/fi1808200412.htm\# =; FORNAZARI , F K. Instituições do Estado e políticas de regulação e incentivo ao cinema no Brasil: o caso Ancine e Ancinav. RAP 40(4):647-77, jul./ago. 2006. Disponível em: http://www.scielo.br/pdf/rap/v40n4/31600.pdf. 
será a audiência capturada. Neste sentido, o êxito da Rede Globo, ao longo de décadas, tem sido, sem dúvida, notável.

Não deixa, por isso, de ser uma visão simplista, "comemorar", como muitos têm feito de uns tempos para cá, a queda de audiência da Rede Globo, ou de circulação da Veja. De fato, tem havido uma lenta, gradual e segura mudança dos hábitos de audiência ou circulação, em prejuízo não apenas da Globo ou da Veja, mas do conjunto da assim chamada "velha mídia". A televisão aberta vem sendo substituída, no gosto popular, pela TV por assinatura ou pelas "novas mídias" da internet. Também a imprensa escrita, do mesmo modo, vem dando lugar à internet, na busca por notícias ou entretenimento. Sobretudo as novas gerações pouco se interessam pelas "velhas mídias".

Por outro lado, do ponto de vista cultural geral ou, se preferirem, político-ideológico, não há nada a "comemorar" por essa mudança. Basta verificar quais são os canais YouTube preferidos, ou os perfis de Facebook ou Twitter que atraem mais seguidores, bem como os canais da TV por assinatura com mais audiência. Nestes aliás, prevalecerão justo os canais das Organizações Globo. A mesma sociedade capitalista do espetáculo, antes veiculada e mobilizada pela "velha mídia", agora vem sendo veiculada e mobilizada, com muito mais eficácia, pelos canais ESPN ou HBO, pelos "like" do You Tube ou Facebook etc. Dá-se, por aí, uma mundialização inaudita e sem barreiras da cultura consumista estadunidense, do "mundo Coca-Cola" ou "mundo McDonald". Pelas redes de TV por assinatura ou da internet, o capital (e sua ideologia imperial estadunidense) se reafirma e se reproduz num processo que todos nós sorvemos quase inconscientemente porque insosso, inodoro, sobretudo indolor...

Um país como o Brasil, que se encontra entre as 10 maiores economias do mundo e tem pretensões de participar dos debates sobre os destinos mundiais, não pode renunciar a se fazer presente nessas arenas também com a sua própria língua e cultura. E os meios devem cumprir esse papel - mesmo que seus controladores não o queiram! É buscando isso que a União Europeia vem construindo, há quase 20 anos, um pacto em defesa da sua cultura (e indústria) audiovisual, concretizado nas suas diretrizes "Televisão Sem Fronteiras", e em toda a sua estrutura normativa para as telecomunicaçõesiii.

O Brasil muito teria a aprender com a norma europeia que, entre outros aspectos, favoreceu uma verdadeira explosão cambriana do número de canais de televisão em todos os países da Europa. Na maioria, existem hoje mais de 200 canais de televisão; em alguns, como Espanha ou Reino Unido, mais de mil, contra apenas 10 ou 20, no início do século. Observe-se, no entanto (e isto é muito importante) que "canal de televisão", aí, não é apenas aquele veiculado pelas frequências atmosféricas, mas também os veiculados pelas frequências hertzianas a cabo ou via satélite. De fato (e isto é muito importante), as frequências atmosféricas são escassas (7 canais de VHF, cerca de 50 de UHF); mas se considerarmos também as centenas de canais possíveis via cabo ou satélite, e ainda os viabilizados pela tecnologia digital, sem falar da banda larga fixa e móvel, aí sim poder-se-ia pensar, como os europeus pensaram, numa política estratégica visando não apenas fomentar a competição ("regulação econômica"?), mas também a diversidade político-cultural e o fomento à cultura nacional, abrindo canais para que vozes e imagens dissonantes possam ocupar seus espaços ao lado da forte indústria cultural que (ainda) temos. Implica dizer, o projeto de regulação não deve se limitar à radiodifusão aberta, ou "terrestre", mas sim, nos termos do artigo 222, § 30 da Constituição, ao conjunto dos meios de comunicação social eletrônica, nestes incluídos não somente a radiodifusão atmosférica, mas a TV por assinatura (aprimorando a Lei 12.485/2011), a internet

iii Para as diretrizes "Televisão sem fronteiras", ver o Jornal Oficial da Comunidade Europeia, 17/10/1989; 24/04/2002; 15/04/2010 em http://publications.europa.eu/official/index_pt.htm; ver também Observatório Europeu do Audiovisual, La Télévision sans frontière dans l'Union Européenne: impacts sur les marchés et aspects juridiques choisis, em www.obs.coe.int/online publication/ transfrontier tv.pdf.fr [citado em 22 maio 2013]. Para a estrutura das telecomunicações, ver European Comission, Towards a new framework for Electronic Communiations Infrastructure, em www.ictregulationtoolkit.org/en/Document.1501.pdf [cita-do em 23 fev. 2015]. Para uma análise circunstanciada dessa legislação, ver DANTAS, M. Comunicações, Desenvolvimento, Democracia, em http:// www.fpabramo.org.br/forum2013/wp-content/uploads/2013/11/6Dantas.pdf, p. 121-133. 
(aprofundando o Marco Civil) e mesmo novidades como o Netflix. Sim, é um senhor desafio! O maior que o novo ministro e sua equipe, apoiados no debate democrático e na mobilização popular, deveriam estar dispostos a enfrentar. É... mas o problema seguirá sendo justo o gosto... popular.

\section{Imprensa, espetáculo e comunicação social eletrônica}

E a imprensa? Sim, uma coisa é a "mídia" enquanto campo sociotécnico de entretenimento, espetáculo e agenciamento cultural. Outra coisa, é um segmento da "mídia", definido como imprensa, ou jornalismo, seja impresso, seja audiovisual. A Constituição é clara ao definir os princípios que devem orientar as concessões de rádio e TV, inclusive demais "meios de comunicação social eletrônica". Mas também é clara quanto à defesa da liberdade de expressão e de imprensa. Na verdade, não se estará regulando a imprensa, mas sim os "meios de comunicação social eletrônica". Entender este ponto e, daí, esclarecê-lo pode vir a ser também um desafio, até para as autoridades que nem sempre conseguem fazer a correta distinção e se deixam enredar no enviesadamente falso debate que confunde "regulação" com "censura"iv.

Não haverá censura à imprensa, constitucionalmente impossível e democraticamente indesejável. Haverá, ou deveria haver, a subordinação dos meios de comunicação social eletrô-nicos, inclusive mas não só a radiodifusão aberta, ao que determinam os artigos 221, 222 e 223 da Constituição, embora também todos os veículos de comunicação devam vir a obedecer, na forma da lei regulatória, aos parágrafos 3, 4 e 5 do artigo 220 (sobre publicidade e sobre monopólio).

É o parágrafo $5^{\circ}$ que sugere a chamada "regulação econômica" para coibir monopólios. De novo, será necessário insistir que o problema não se limita à radiodifusão aberta mas abrange, até com mais gravidade, a radiodifusão fechada e paga, cuja infraestrutura tende a ser controlada por um pequeno número de grandes operadoras de telecomunicações (Telefónica, Embratel, Oi, Sky) e cuja multiplicidade de canais (isto que efetivamente leva alguém a assinar algum "pacote") é organizada e ofertada por cerca de quatro ou cinco grandes conglomerados mundiais, a saber: Time-Warner, Disney, Viacom, News Corp e... Organizações Globo.

Muito mais importante será entender que, falando de gosto, não estamos falando de sabonetes ou verduras... Regras antimonopolistas nos termos dos teóricos walrasianos podem se aplicar a bens materiais divisíveis em unidades iguais e padronizadas, os chamados "bens rivais". Ou seja, as mercadorias. Muito dificilmente funcionam em mercados de bens intangíveis indivisíveis, "não rivais", ou seja, informações. A solução ao que parece, de novo conforme a lição europeia, seria introduzir, com alguma chance de êxito, uma clara distinção econômica-empresarial, no interior da cadeia produtiva, entre os agentes que produzem e programam, e os agentes que transportam e distribuem. Trata-se de coibir o controle vertical do conjunto das etapas do processo produtivo. A Lei 12.485/2011 e o Marco Civil da Internet adotaram tal princípio, conhecido como regulação por camadas. O já citado Projeto de Lei de Iniciativa Popular para regular os meios também sugere introduzi-lo inclusive na radiodifusão aberta, como já acontece na Europa. Mas a resistência, temos visto, será poderosa.

Em suma, se o debate que o ministro Berzoini propõe nos permitir avançar para além da globofobia reinante e daí entender, realmente, a complexidade estratégica que nos convoca a uma aprofundada discussão sobre o capitalismo mediatizado e o lugar do Brasil nele, já teremos, pelo menos, vencido o maior de todos os desafios do quadriênio e poderemos começar a sonhar com a construção de um sistema regulatório avançado e democrático para as nossas comunicações.

iv Ver Decálogo sobre censura e regulação, Carta Maior, Disponível em: http://cartamaior.com.br/?/Editoria/Midia/Decalogo-sobrecensura-e-regulacao/12/32431. 